\title{
Postpartum Pyrexia
}

National Cancer Institute

\section{Source}

National Cancer Institute. Postpartum Pyrexia. NCI Thesaurus. Code C114405.

A sustained temperature of 38C (100.4F) or greater beyond the first 24 hours following birth, or a temperature of $39 \mathrm{C}(102.2 \mathrm{~F})$ within the first 24 hours following birth. (adapted from ACOG) 